\title{
Comparative in vitro study of two methods for gingival biotype assessment
}

\author{
Leticia Sala $^{1}$, Raquel Alonso-Pérez ${ }^{2}$, Ruben Agustin-Panadero ${ }^{3}$, Alberto Ferreiroa ${ }^{4}$, Ana Carrillo-de-Albornoz ${ }^{5}$ \\ ${ }^{1}$ Professor, Department of Periodontology, School of Dentistry, Mississippi Institution of Madrid. Spain \\ ${ }^{2}$ Researcher, Department of Prosthodontics. School of Dentistry, Complutense University of Madrid. Spain \\ ${ }^{3}$ Adjunct professor, Department of Stomatology, Faculty of Medicine and Dentistry, University of Valencia. Spain \\ ${ }^{4}$ Associate Professor, Department of Restorative Dentistry and Buccofacial Protheses. School of Dentistry, Complutense Univer- \\ sity of Madrid. Spain \\ ${ }^{5}$ Associate Professor, Department of Periodontology. School of Dentistry, Complutense University of Madrid. Spain
}

Correspondence:

C/ Santísima Trinidad 5

28010. Madrid. Spain

letisala@hotmail.com

Received: $27 / 05 / 2018$

Accepted: 08/06/2018
Sala L, Alonso-Pérez R, Agustin-Panadero R, Ferreiroa A, Carrillo-de-Albornoz A. Comparative in vitro study of two methods for gingival biotype assessment. J Clin Exp Dent. 2018;10(9):e858-63.

http://www.medicinaoral.com/odo/volumenes/v10i9/jcedv10i9p858.pdf

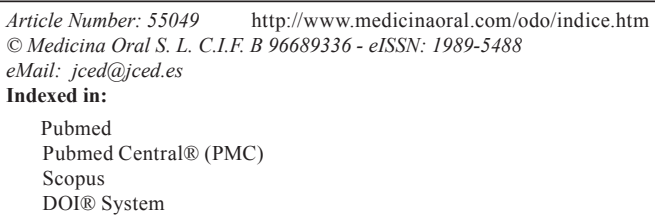

\begin{abstract}
Background: The gingival thickness seems to have an important role in different dental treatments. There are different methods of quantifying this thickness, but it is not known which of them can be the most effective. The objective to assess the accuracy of two different methods for gingival thickness measurement: the transgingival needle probing (TGNP) and the tension-free caliper (TFC) in an in vitro model, by comparing them with direct physical measurements (reference standard).

Material and Methods: Gingival thickness (GT) was evaluated in 27 female pigs with four implant sites 1, 2 and $3 \mathrm{~mm}$ from the gingival margin with three different methods: 1) transgingival needle probing 2) tension-free caliper and 3) Direct visualization after making a incision in the mucosa and measuring GT with a periodontal probe. Wilcoxon test for paired samples were used with a confident level of $95 \%$

Results: A total of 324 points were measured, $59 \%$ of the sites presented a thin biotype with DV, it was correctly assessed with the TGNP in $84 \%$ of the times and in $86 \%$ with the TFC. $41 \%$ of the sample presented thick biotype, $76 \%$ was the percentage measured with the TGNP and $0 \%$ of the sites evaluated with TFC resulted in this biotype. Conclusions: Transgingival needle probing constitutes an accurate method when measuring GT at different levels. Tension free caliper is not a good tool for assessing the gingival biotype as long as it is unable to predict thick biotype.
\end{abstract}

Key words: Periodontal Biotype, Gingival Thickness, Periodontal Tissue and Diagnosis.

\section{Introduction}

Recently scientific interest has focused to determine the influence of gingival biotypes on dental treatments. Gingival biotype is described as the thickness of the gingiva in the faciopalatal dimension (1). It has demonstrated to exhibit a significant impact on the outcome of restorati- ve therapy (2-4). The influence of the gingival thickness seems to be an important factor to take into account in the diagnosis of dental treatment as it plays an important role in wound healing in regenerative surgical procedures (1). It can also prevent complications due to orthodontic treatments (5) and helps to achieve predictable 
and esthetic outcomes in implantology (6-8). A direct correlation has been established between gingival biotype and its susceptibility to suffer recession after surgical and restorative procedures being the thin one the most susceptible to this phenomenon $(9,10)$. Moreover, it has been documented in literature greater mean bone loss occurring around implants in sites with thin biotype compared to thick overlying mucosa (8).

Hence, a proper diagnosis of the periodontal biotype seems to be of great interest in order to take decisions (11) in implant dentistry. It can also be a tool for clinicians as they can quantify and monitor gingival changes through the treatment $(12,13)$.

Claffey and Shanley (14) defined the thin tissue biotype as a gingival thickness $<1.5 \mathrm{~mm}$, while the thick tissue biotype was referred as tissue thickness $\geq 2 \mathrm{~mm}$. Several methods have been proposed to measure gingival thickness:1) invasive methods such as transgingival probing (TRAN) (15) or the use of an endodontic file (15-17); 2) non-invasive techniques such as probe transparency through the free gingiva $(7,18)$, plaster models(19), ultrasonic devices $(20,21)$, the modified caliper $(6,22)$, and most recently the Cone-Beam Computed Tomography (CBCT) $(17,23)$ and the "puffed cheek" method (computed tomography scans with distended cheeks) (24).

The validity of ultrasound devices and computed tomography methods have been widely studied $(17,25,26)$. However, the most frequently used method is the one that measure the visibility of the instrument when probing $(7,18)$. The use of a tension free caliper to perform a direct measurement has also been used for many authors, even though it cannot be used for pretreatment evaluation $(6,22)$, it can be useful for measuring the gingival thickness on implants previous to the prosthetic treatment or after tooth extraction. In general, methods currently used to discriminate thin from thick gingiva have shown limited reliability and accuracy (27).

This lack of accuracy, described as the amount of agreement between the information from the test under evaluation and the reference standard, in the methods and indices to evaluate the soft tissues make difficult to establish a definition of the gingival esthetic parameters in relation to successful implant restorations(10).

This in vitro study has the outcome to assess the accuracy of two different methods for gingival thickness measurement: the transgingival needle probing and the tension free-caliper in an in vitro model, by comparing them with direct physical measurements (reference standard).

\section{Material and Methods}

An in vitro study was conducted in fresh mandibles of female pigs to evaluate the gingival thickness (GT). This study is reported according to the Standards for Reporting of Diagnostic Accuracy (STARD) (28).
-Sample size calculation

The sample size estimation was calculated for $\sqrt{ }=0.05$ and a power (1- $\beta$ ) of $80 \%$. A variability of $0.5 \pm 0.2 \mathrm{~mm}$ was considered to be clinically relevant based on the results of previous studies (13). The sample size equaled 11 subjects but it was increased to 27 for robust data achievement.

-Experimental animals

Female pigs aged between 1 and 1.5 years were controlled for diet, temperature, and light exposure under Spanish standards for animal care before their sacrifice. The farms supplying the animals were organized in accordance with EU and Spanish legislation against cruelty to animals. The study protocol of the study was approved by the Medical Ethics Commission of the University of Alcalá de Henares (Madrid, Spain).

The following inclusion criteria were adopted: fresh mandible less than $24 \mathrm{~h}$ after the death of the animal; presence of edentulous sites and adjacent teeth with similar gingival architecture in optimal conditions; and study areas with at least $4 \mathrm{~mm}$ of keratinized mucosa. Animals were recruited consecutively from the farm, and they were discarded if they did not fulfill the inclusion criteria. Each animal provided four implant sites, and on each one GT was measured at 1,2 and $3 \mathrm{~mm}$ from the gingival margin, providing a totally of 324 study areas. Two animals were studied per day, and all measurements were done after a 6 months period.

-Data collection

GT was evaluated by three different methods by the same operator (L.S.):

1) Transgingival needle probing (TGNP). An anesthesic needle was fitted with a rubber stopper (Normon Jet Plus $0.3 \times 12 \mathrm{~mm}$, Normon, Tres Cantos, Madrid, Spain). Previously, an abutment was placed in the implant (3inOne PYREA; $3.5 \mathrm{~mm}$ regular emergence profile, Biohorizons, Birmingham, AL, USA). The needle was placed perpendicularly into the mucosa in the points marked 1 , 2 and $3 \mathrm{~mm}$ apical to the gingival margin. The rubber stopper shifted along the needle while it went through the soft tissue until the abutment surface was reached. The distance between the needle tip and the silicone stopper was measured. This measurement was taken as the GT (Fig. 1). Once all the sites were registered, the abutment was retired and the operator proceeded to evaluate the GT with the next method.

2) Tension free caliper (Iwanson DP 720, Italy) (TFC). Before starting, it was modified by cutting the spring to eliminate the tension in order to avoid excessive pressure on the soft tissue (Fig. 2). Thickness was then determined with the caliper at the points marked at 1,2 and $3 \mathrm{~mm}$ apical to the gingival margin. When the measurements with this method were finished, the operator started with the last procedure.

3) Direct visualization measurements (DV) were done 


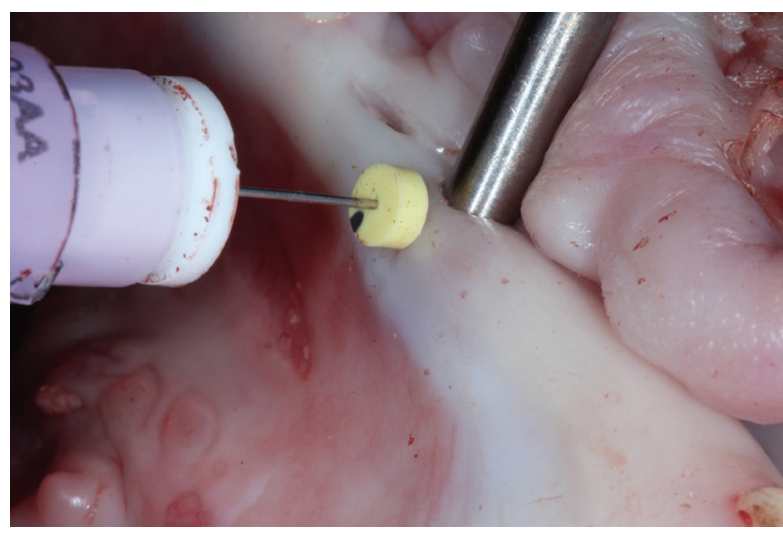

Fig. 1: Transgingival needle probing (TGNP). Needle through the mucosa with a rubber stopper.

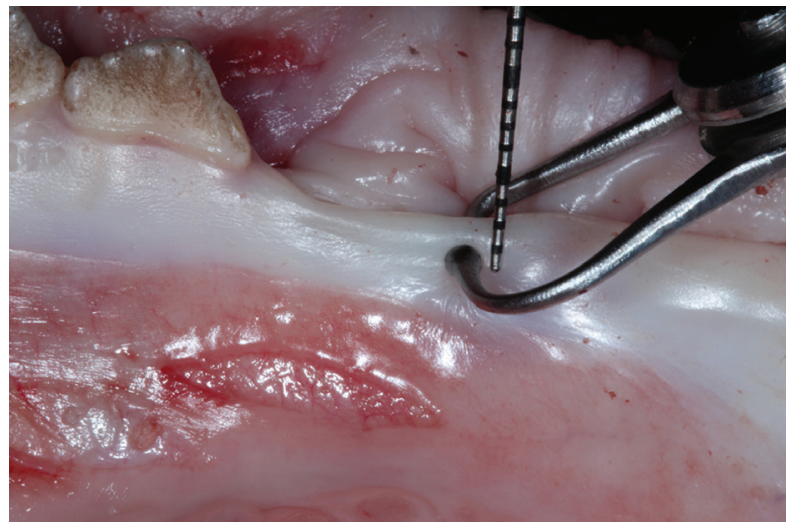

Fig. 2: Tension-free caliper. Caliper measuring GT at $2 \mathrm{~mm}$ from the gingival margin.

with a periodontal probe graduated in $1 \mathrm{~mm}$ increments (CPC-15 periodontal probe, Hu-Friedy, Leinmen, Germany). These measurements were taken directly on an incision made in the central axis of the implant (Fig. 3). The direct measurement of the thickness with the periodontal probe was considered for the authors as the reference standard.

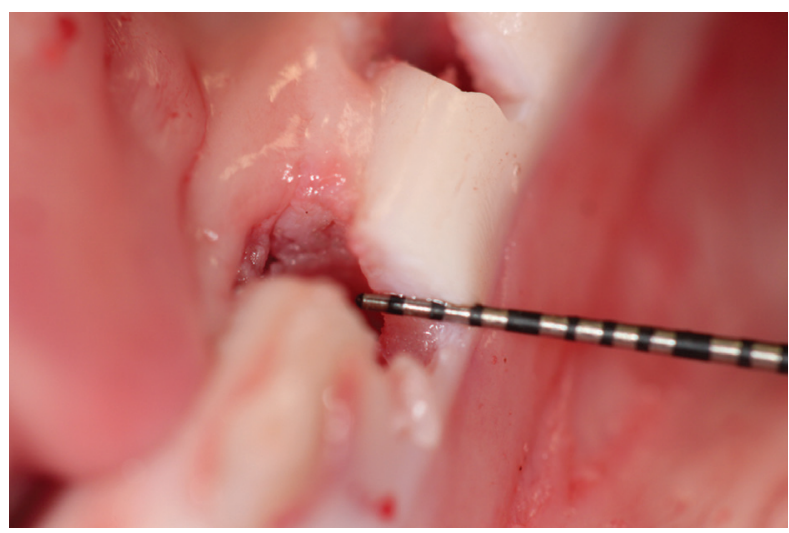

Fig. 3: Direct visualization enables a direct measurement with a millimeter probe.
-Statistical analysis

The subject (animal) was the unit for the basic statistical analysis. Means and standard deviation were calculated for the gingival tissue thickness. Data were expressed as medians and $95 \%$ confidence intervals. Normal distribution of continuous variables studied by the Kolmogorov-Smirnov test was not confirmed; therefore data were compared using nonparametric analysis. Wilcoxon signed rank test was used to assess differences in the GT evaluated by direct measurements (gold standard) and by two other measurement systems. Paired analysis using the same statistical test were performed after stratifying the samples according to thickness $(<1 \mathrm{~mm} ; 1-2$ and $\geq 2 \mathrm{~mm}$ ). Alpha error was set at $p<0.05$.

\section{Results}

The GT of 108 implants placed in 27 mandibles from female pigs was studied between February 2013 and June 2014, after application of the study criteria described before. A total of twelve measurements per specimen were made at $1 \mathrm{~mm}, 2$ and $3 \mathrm{~mm}$ apical to the central aspect of the periimplant margin (soft tissue height incremental areas) of each implant, where soft tissue mean thicknesses obtained with the reference standard (DV) were $1.15 \pm 0.49 \mathrm{~mm}, 1.42 \pm 0.65 \mathrm{~mm}$ and $1.54 \pm 0.76 \mathrm{~mm}$ respectively.

-Test Results.

Table 1 summarizes the descriptive data recorded for the GT measurements and the reference standard.

According to the results $59 \%$ of the measurements were classified as thin biotype and $41 \%$ as thick biotype. With the TGNP, the thin biotype was correctly assessed in $84 \%$ of the sites and the thick biotype in $76 \%$. TFC was successful in assessing the thin biotype in $86 \%$ of the situations, in contrast, for the thick biotype the percentage of hit was $0 \%$.

Table 2 displays the Wilcoxon analysis for the accuracy data, which reveal statistically significant differences between TFC and DV (reference standard) at $1 \mathrm{~mm}$ $(p<0.001), 2 \mathrm{~mm}(p<0.001)$, and $3 \mathrm{~mm}(p<0.005)$ from the gingival margin. No significant differences were observed between the TGNP method and the reference standard (DV) at none of the measured areas.

\section{Discussion}

This in vitro model was designed to determine the accuracy of peri-implant mucosa thickness by measuring it in the midfacial aspect of 108 implants placed in 27 animal mandibles. Differences between methods were detected, finding TGNP more accurate than TFC.

The invasive methods of assessing GT using an injection needle or a probe have been used traditionally by many authors (14,29-31). In 2003, Kan et al. (18) introduced a non invasive method which was based on the transparency of periodontal probe. It categorized the biotype as 
Table 1: GT mean, standard deviation (SD), minimum (Min) and maximum (Max) values in mm for TGNP, TC and DV methods.

\begin{tabular}{|l|l|l|l|l|l|}
\hline & \multicolumn{1}{|c|}{$\mathrm{n}$} & mean & SD & Min & Max \\
\hline TGNP 1mm & 108 & 1.16 & 0.53 & -0.20 & 0.32 \\
\hline TFC 1 mm & 108 & 0.85 & 0.39 & -0.12 & 0.18 \\
\hline DV 1 mm & 108 & 1.15 & 0.49 & -0.18 & 0.31 \\
\hline TGNP 2mm & 108 & 1.49 & 0.65 & -0.14 & 0.21 \\
\hline TFC 2mm & 108 & 1.08 & 0.45 & -0.09 & 0.20 \\
\hline DV 2mm & 108 & 1.42 & 0.65 & -0.15 & 0.26 \\
\hline TGNP 3mm & 108 & 1.56 & 0.73 & -0.14 & 0.24 \\
\hline TFC 3mm & 108 & 1.29 & 0.57 & -0.01 & 0.16 \\
\hline DV 3mm & 108 & 1.54 & 0.76 & -0.12 & 0.19 \\
\hline
\end{tabular}

Table 2: Wilcoxon test for paired samples comparing the tested methods with the reference standard.

\begin{tabular}{|l|c|c|}
\hline GT location & TGNP vs DV & TFC vs DV \\
\hline $1 \mathrm{~mm}$ & $p=0.173$ & $p=0.000^{\circ}$ \\
\hline $2 \mathrm{~mm}$ & $p=0.844$ & $p=0.001^{\circ}$ \\
\hline $3 \mathrm{~mm}$ & $p=0.881$ & $p=0.025^{\circ}$ \\
\hline & $\begin{array}{l}p<0.005 \text { Statistically } \\
\text { significant }\end{array}$ & \\
\hline
\end{tabular}

thin if the underlying of the periodontal probe was visible through the gingival or thick if not. This method has been widely used for biotype discrimination $(7,10,32)$ and authors have considered it as a gold standard (33) even though it has been demonstrated that less than the $50 \%$ of biotypes are correctly assessed by experienced dentists (3).

TGNP using an injection needle or an endodontic tool with a silicone limiter seems to be accepted as an accurate method despite it has not been scientifically validated for that purpose $(13,34,35)$. Our results confirm that it is an accurate system for GT evaluation as no differences $(p>0.005)$ with the measurements obtain by DV measurements (gold standard) were observed neither at 1,2 or $3 \mathrm{~mm}$ points measured from gingival margin. These results indicate that GT assessment with TGNP is a reliable method no matter the thickness of the study area. If we consider the classification of Claffey et al. (14) (thin $<1.5 \mathrm{~mm}$; thick $\geq 2 \mathrm{~mm}$ ), the thin biotype was correctly assessed in $84 \%$ of the sites measured, and the thick biotype in $76 \%$.

When comparing this method with the Computed tomography (CT) a strong correlation between the two procedures could not be found (34). The authors concluded that $\mathrm{CT}$ is not as reliable as needle probing as it seems to overestimate the true thickness in areas with thin gingiva. However, the CBCT has been described as a useful method to assess palatal mucosal thickness $(17,25)$ and for biotype classification (26). By contrast, Fu et al. (36) stated that $\mathrm{CBCT}$ provides accurate measurements of soft tissue thickness. They concluded that it is a more objective method to define the thickness of soft tissues than direct measurements.

Some authors $(21,37,38)$ have proposed the use of a specially-designed ultrasonic dental system as a diagnostic tool for gingival thickness determination. Only one study (21) have compared the ultrasonic device with the transgingival method in an in vitro model, concluding that some errors are associated with the invasive technique and recommending the ultrasound method for non invasive GT assessment.

Our results are in consonant with some authors that affirm that even though the CT methods and ultrasonic devices are suitable and painless techniques for obtaining GT (23), the unavailability(39) and high costs(26) associated with these systems are disadvantages to take into consideration. Simple measurements performed with a periodontal probe are often part of routine diagnostics, which are carried out quickly without special appliances or preparations (13).

The use of a TFC for direct gingival thickness measurements has also been studied by many authors $(6,22,36)$. Kan et al. (6) even considered it as a gold standard to validate other methods. However, the caliper has not been scientifically evaluated for this purpose and our results found it not reliable for thickness evaluation as signifi- 
cant differences were observed $(p<0.001)$ with respect to our reference standard. Especially when assessing the thick biotype, the caliper failed in $100 \%$ of the cases, while for the thin biotype failed just $14 \%$ of the times. This lack of accuracy for assessing thick biotypes may be due to a compression of the soft tissues, suspecting that the spring cut of the caliper could not be valid for eliminating the tension.

Besides the inherent limitations of an in vitro model, the major weakness of the study is the lack of consensus of a precise definition for thick and thin biotype. The lack of studies about reliability and accuracy of biotype assessment makes difficult to compare the results of this research, therefore the external validity of our study is limited.

Within the limitations of this in vitro study, the present data support the following conclusions:

(i) The transgingival needle probing is an accurate method for gingival thicknesses measurements at different vertical levels from the margin.

(ii) The spring modified caliper is not valid for gingival biotype determination, especially for thick biotype, where it tends to infra-measure the real thickness of the mucosa.

\section{References}

1. Kao RT, Fagan MC, Conte GJ. Thick vs. thin gingival biotypes: a key determinant in treatment planning for dental implants. J Calif Dent Assoc. 2008;36:193-8.

2. Nisapakultorn K, Suphanantachat S, Silkosessak O, Rattanamongkolgul S. Factors affecting soft tissue level around anterior maxillary single-tooth implants. Clin Oral Implants Res. 2010;21:662-70.

3. Eghbali A, De Rouck T, De Bruyn H, Cosyn J. The gingival biotype assessed by experienced and inexperienced clinicians. J Clin Periodontol. 2009;36:958-63.

4. Cosyn J, Sabzevar MM, De Bruyn H. Predictors of inter-proximal and midfacial recession following single implant treatment in the anterior maxilla: a multivariate analysis. J Clin Periodontol. 2012;39:895903.

5. Anderegg CR, Metzler DG, Nicoll BK. Gingiva thickness in guided tissue regeneration and associated recession at facial furcation defects. J Periodontol. 1995;66:397-402.

6. Kan JYK, Morimoto T, Rungcharassaeng K, Roe P, Smith DH. Gingival biotype assessment in the esthetic zone: visual versus direct measurement. Int J Periodontics Restorative Dent. 2010;30:237-43.

7. De Rouck T, Eghbali R, Collys K, De Bruyn H, Cosyn J. The gingival biotype revisited: transparency of the periodontal probe through the gingival margin as a method to discriminate thin from thick gingiva. J Clin Periodontol. 2009;36:428-33.

8. Vervaeke S, Dierens M, Besseler J, De Bruyn H. The influence of initial soft tissue thickness on peri-implant bone remodeling. Clin Implant Dent Relat Res. 2014;16:238-47.

9. Kan JYK, Rungcharassaeng K, Morimoto T, Lozada J. Facial gingival tissue stability after connective tissue graft with single immediate tooth replacement in the esthetic zone: consecutive case report. J Oral Maxillofac Surg. 2009;67:40-8.

10. Evans CDJ, Chen ST. Esthetic outcomes of immediate implant placements. Clin Oral Implants Res. 2008;19:73-80.

11. Zweers J, Thomas RZ, Slot DE, Weisgold AS, Van der Weijden FGA. Characteristics of periodontal biotype, its dimensions, associations and prevalence: a systematic review. J Clin Periodontol. 2014;41:958-71.
12. Kois JC. Predictable single tooth peri-implant esthetics: five diagnostic keys. Compend Contin Educ Dent. 2001;22:199-206.

13. Ronay V, Sahrmann P, Bindl A, Attin T, Schmidlin PR. Current status and perspectives of mucogingival soft tissue measurement methods. J Esthet Restor Dent. 2011;23:146-56.

14. Claffey N, Shanley D. Relationship of gingival thickness and bleeding to loss of probing attachment in shallow sites following nonsurgical periodontal therapy. J Clin Periodontol. 1986;13:654-7.

15. Savitha B, Vandana KL. Comparative assesment of gingival thickness using transgingival probing and ultrasonographic method. Indian J Dent Res. 2005;16:135-9.

16. Muller HP, Schaller N, Eger T, Heinecke A. Thickness of masticatory mucosa. J Clin Periodontol. 2000;27:431-6.

17. Barriviera M, Duarte WR, Januario AL, Faber J, Bezerra ACB. A new method to assess and measure palatal masticatory mucosa by cone-beam computerized tomography. J Clin Periodontol. 2009;36:564-

18. Kan JYK, Rungcharassaeng K, Umezu K, Kois JC. Dimensions of peri-implant mucosa: an evaluation of maxillary anterior single implants in humans. J Periodontol. 2003;74:557-62.

19. van Brakel R, Noordmans HJ, Frenken J, de Roode R, de Wit GC, Cune MS. The effect of zirconia and titanium implant abutments on light reflection of the supporting soft tissues. Clin Oral Implants Res. 2011;22:1172-8

20. Chang M, Odman PA, Wennstrom JL, Andersson B. Esthetic outcome of implant-supported single-tooth replacements assessed by the patient and by prosthodontists. Int J Prosthodont. 1999;12:335-41.

21. Slak B, Daabous A, Bednarz W, Strumban E, Maev RG. Assessment of gingival thickness using an ultrasonic dental system prototype: A comparison to traditional methods. Ann Anat. 2015;199:98-103. 22. Bressan E, Paniz G, Lops D, Corazza B, Romeo E, Favero G. Influence of abutment material on the gingival color of implant-supported all-ceramic restorations: a prospective multicenter study. Clin Oral Implants Res. 2011;22:631-7.

23. Benic GI, Elmasry M, Hammerle CHF. Novel digital imaging techniques to assess the outcome in oral rehabilitation with dental implants: a narrative review. Clin Oral Implants Res. 2015;26 Suppl 1:86-96.

24. Weissman JL, Carrau RL. "Puffed-cheek" CT improves evaluation of the oral cavity. AJNR Am J Neuroradiol. 2001;22:741-4.

25. Song JE, Um YJ, Kim CS, Choi SH, Cho KS, Kim CK, et al. Thickness of posterior palatal masticatory mucosa: the use of computerized tomography. J Periodontol. 2008;79:406-12.

26. Januario AL, Barriviera M, Duarte WR. Soft tissue cone-beam computed tomography: a novel method for the measurement of gingival tissue and the dimensions of the dentogingival unit. J Esthet Restor Dent. 2008;20:366-73.

27. Cuny-Houchmand M, Renaudin S, Leroul M, Planche L, Guehennec L Le, Soueidan A. Gingival biotype assessement: visual inspection relevance and maxillary versus mandibular comparison. Open Dent J. 2013;7:1-6.

28. Bossuyt PM, Reitsma JB, Bruns DE, Gatsonis CA, Glasziou PP, Irwig LM, et al. The STARD statement for reporting studies of diagnostic accuracy: explanation and elaboration. The Standards for Reporting of Diagnostic Accuracy Group. Croat Med J. 2003;44:639-50. 29. Goaslind GD, Robertson PB, Mahan CJ, Morrison WW, Olson J V. Thickness of facial gingiva. J Periodontol 1977;48:768-71.

30. Olsson M, Lindhe J. Periodontal characteristics in individuals with varying form of the upper central incisors. J Clin Periodontol. 1991;18:78-82.

31. Studer SP, Allen EP, Rees TC, Kouba A. The thickness of masticatory mucosa in the human hard palate and tuberosity as potential donor sites for ridge augmentation procedures. J Periodontol. 1997;68:14551.

32. Cook DR, Mealey BL, Verrett RG, Mills MP, Noujeim ME, Lasho DJ, et al. Relationship between clinical periodontal biotype and labial plate thickness: an in vivo study. Int J Periodontics Restorative Dent. 2011;31:345-54 
33. Frost NA, Mealey BL, Jones AA, Huynh-Ba G. Periodontal Biotype: Gingival Thickness as It Relates to Probe Visibility and Buccal Plate Thickness. J Periodontol. 2015;86:1141-9.

34. Dvorak G, Arnhart C, Schon P, Heuberer S, Watzek G, Gahleitner A. The "puffed cheek method" to evaluate mucosal thickness: case series. Clin Oral Implants Res. 2013;24:719-24.

35. Maia LP, Reino DM, Muglia VA, de Souza SLS, Palioto DB, Novaes $A B J$. The influence of the periodontal biotype on peri-implant tissues around immediate implants with and without xenografts. Clinical and micro-computerized tomographic study in small Beagle dogs. Clin Oral Implants Res. 2015;26:35-43.

36. Fu JH, Yeh CY, Chan HL, Tatarakis N, Leong DJM, Wang HL. Tissue biotype and its relation to the underlying bone morphology. $\mathrm{J}$ Periodontol. 2010;81:569-74.

37. Muller HP, Schaller N, Eger T. Ultrasonic determination of thickness of masticatory mucosa: a methodologic study. Oral Surg Oral Med Oral Pathol Oral Radiol Endod. 1999;88:248-53.

38. Eger T, Muller HP, Heinecke A. Ultrasonic determination of gingival thickness. Subject variation and influence of tooth type and clinical features. J Clin Periodontol 1996;23:839-45.

39. Vandana KL, Savitha B. Thickness of gingiva in association with age, gender and dental arch location. J Clin Periodontol. 2005;32:82830 .

Conflict of interest

The authors of this research declare no competing financial interests. 